\title{
Dioses y semidioses en la construcción de la nación venezolana. El centauro llanero, José Antonio Páez
}

\author{
Deuses e semideuses na construção da nação venezulana. O centauro llanero, \\ JoséAntonio Páez
}

Deities and demigods in the construction of the venezuelan nation. The centauro llanero, Jose Antonio Paez

Ernesto Mora Queipo

Jean González Queipo

Dianora Richard deMora

\section{Resumen}

Este artigo, dedicado ao estudo do nacionalismo e da independência da nação venezuelana, centra-se na representação coletiva do general Páez, como o Centauro Llanero, pois, sob essa égide, dessa mítica figura nasceu, em 1830, como nação livre e independente da Gran Colombia, a República da Venezuela. Ao interpretar essa figura no contexto independentista, se evidencia que os mitos fundacionais das nações latino-americanas atuais se constroem com as releituras dos antigos mitos das sociedades ocidentais, indo-americanas e afro-americanas. A definição daqueles mitos, com seus heróis e anti-heróis, opressores e libertadores, deu fundamento às representações, etnicidades e ideologias que, sob as rou- pagens do nacionalismo, produziram a erosão dos impérios e o surgimento das repúblicas atuais.

Palavras-chave: Guerra de Independência. Mitos fundacionais. Símbolos identitários.

* Doctor en Ciencias Humanas y Magister en Antropologia Social y Cultural; Docente e investigador en La Universidad del Zulia (Maracaibo-Venezuela).

** Magister en Composición; Docente e investigador en La Universidad del Zulia (Maracaibo-Venezuela).

**** Magister en Planificación y Gerencia de Ciencia y Tecnología; Docente e investigadora en La Universidad Bolivariana de Venezuela.

Recebido em: 25/09/2012 - Aprovado em: 12/02/2013 http://dx.doi.org/10.5335/hdtv.13n.1.3000 


\section{Introducción}

Las luchas independentistas de la América hispana hicieron uso de complejos procesos socioculturales, para representar la decadencia del imperio español, del rey y de su sacralidad; y el reemplazo de cada uno de aquellos aspectos con los propios de una nueva realidad republicana. Si bien, uno de los escenarios de lucha fue el campo de batalla, es evidente que esa movilización y enfrentamiento dependió en muchos casos de la construcción y manipulación de símbolos pertenecientes a otro escenario no menos importante: el de "lo sagrado". En ese amplio panorama de lo sacralizado desde la guerra de independencia hasta nuestros días, se destacan dos grandes figuras, Los Libertadores: Simón Bolívar (Caracas, 24/7/1783 - Santa Marta, 17/12/1830) y José de San Martin (Yapeyú, 25/2/ 1778 - Boulogne-sur-Mer, 17/8/1850).

Es evidente que las figuras de estos dos personajes, erigidas actualmente en la gran mayoría de las plazas centrales de nuestros pueblos y ciudades, es una representación material creada bajo la misma dinámica con que son creadas las imágenes de los dioses. En el caso de Bolívar, la impronta de esta mitificación y deificación se extiende y profundiza desde las primeras décadas del siglo XIX hasta nuestros días, cuando -por ejemplo- en cultos religiosos como el de María Lionza “...el héroe nacional (Simón Bolívar-Libertador) toma un carácter divino...".1

Ya en las primeras décadas del XIX, los partidarios de la Independencia expresaban este fenómeno de diferentes formas. Entre ellas pueden señalarse las versificaciones populares que le representaron como poseedor de poderes sobrehumanos para matar españoles europeos y canarios. Esta realidad puede observarse en el juicio que se sigue a cinco hombres, que están presos por haber participado en un baile realizado en la ciudad de Caracas, en diciembre de 1815, ocasión en la cual se cantaron y bailaron joropos con coplas subversivas en honor a Simón Bolívar. La notificación enviada al gobernador de esa ciudad señala:

El Sargento Mayor de la Plaza, D. Antonio Guzmán, participa al Gobernador interino de Caracas, D. Juan Nepomuceno Chourio de un baile en casa de la señora Juana Morales, en el cual cantaban canciones insurrectas, como esta: 'El Gral. Bolívar tiene un caballo, para matar Españoles Europeos y Canarios'. Por esta causa fueron llevados los cinco hombres del baile a la cárcel y puestos sin comunicación. ${ }^{2}$

En las declaraciones que recoge este documento, puede apreciarse la utilización de la música para crear y remarcar las diferencias y oposiciones entre españoles y americanos. La figura guerrera de Bolívar en su veloz y poderoso caballo, es exaltada en diversas composiciones populares; como esta redondilla: 'El General Bolívar, tiene un caballo, que cuando va a la guerra, se vuelve un rayo'"'3.

Este proceso de sacralización del "Padre de la Patria", ha sido estudiado desde diferentes perspectivas en tiempos más recientes, dando lugar a obras que llevan títulos como Bolívar: el hombre de la gloria, ${ }^{4}$ Bolívar el caballero de la gloria y la libertad, ${ }^{5}$ El Culto a Bolívar. ${ }^{6}$

Paradójicamente, frente a la abundante bibliografía dedicada a la sacralización del 
Libertador Simón Bolívar, se encuentra un relativo vacío sobre "El Centauro Llanero, José Antonio Páez"; aunque es evidente que el proceso de construcción simbólica que mitificó y deificó a Bolívar, es el mismo proceso que hizo de la figura ecuestre de Páez un ser sacralizado, que en sus momentos de gloria fue tenido como un semidiós. La significación e importancia de la imagen del centauro llanero, llegó a competir, e incluso a desplazar, a la figura de Bolívar (Padre de la Patria y héroe civilizador por excelencia). Esta sustitución se hace particularmente evidente en el proceso de etnogénesis de Venezuela, toda vez que la Gran Colombia (creada por El Libertador Simón Bolívar, el 17 de diciembre de 1819), es fragmentada en 1830, y es Páez quien acompaña y legitima el nacimiento de Venezuela como nación libre e independiente, convirtiéndose en el Fundador de la República de Venezuela. ${ }^{7}$

\section{José Antonio Páez, el peón del hato La Calzada}

José Antonio Páez (Curpa, 13/6/1790 - Nueva York, 6/5/1873), General en Jefe de la Independencia de Venezuela y Presidente de la República en tres oportunidades, nació el 13 de junio de 1790 en una humilde casa a orillas del río Curpa, cerca de Acarigua, pueblo llanero del estado Portuguesa. Es el penúltimo hijo entre ocho hermanos. Aprendió a leer y escribir en una pequeña escuela de Guama, población donde vivía su madre, María Violante, esposa de Juan Victorio Páez, quien era empleado del estanco del tabaco en Guanare.
Consiguió trabajo en 1807 como peón en el hato de La Calzada, propiedad de don Manuel Pulido. El caporal de aquella hacienda, un negro esclavo apodado Manuelote, exigía a José Antonio Páez domar potros, atravesar ríos a nado e incluso dormir a la intemperie. Allí Páez sufrió los rigores de las más rudas faenas del llano: domando potros se le ampollaron las manos con el cabestro de cerda, y en ocasiones tuvo que montarlos a pelo. Sus muslos sufrieron tales rozaduras con las correas de cuero sin adobar que servían como arzones, que muchas veces sangraron y se infectaron con gusanos. Páez relata esta etapa de su vida en su autobiografía:

La vida de peón fue el gimnasio donde adquirí la robustez atlética que tantas veces me fue utilísima después. Mi cuerpo, a fuerza de golpes, se volvió de hierro y mi alma adquirió, con las adversidades en los primeros años, ese temple que la educación más esmerada difícilmente habría podido darme... Tocóme de capataz un negro alto, taciturno y de severo aspecto, a quien contribuía a hacer más venerable una poblada barba. Apenas se había puesto el novicio a sus órdenes, cuando, con voz imperiosa, le ordenaba que montase un caballo sin rienda, caballo que jamás había sentido sobre el lomo ni el peso de la carga, ni el del domador... El Hato La Calzada se hallaba a cargo de este negro llamado Manuel o, según le decíamos todos, Manuelote, el cual era esclavo de Don Manuel Pulido y ejercía el cargo de mayordomo. Las sospechas que algunos peones le habían hecho concebir a Manuelote, de que, bajo el pretexto de buscar servicio, había ido yo a espiar su conducta, hicieron que me tratase con mucha dureza, dedicándome siempre a los trabajos más penosos, como domar caballos salvajes, sin permitirme montar sino los de esta clase; 
pastorear los ganados durante el día, bajo un sol abrazador, operación que por esta causa y por la vigilancia que exigía era la que yo más odiaba; velar por las noches las madrinas de los caballos para que no se ahuyentasen, cortar con hacha maderos para las cercas, y finalmente arrojarme con el caballo a los ríos, cuando aún no sabía nadar, para pasar como guía los ganados de una ribera a otra. Recuerdo que un día, al llegar a un rio, me gritó: "Tírese al agua y guíe al ganado". Como yo titubease manifestándole que no sabía nadar, me contestó en tono de cólera: "Yo no le pregunto a usted si sabe nadar o no, le mando que se tire al río y guíe al ganado". Mucho sufrî con aquel trato: las manos se me rajaron a consecuencia de los grandes esfuerzos que hacía para sujetar los caballos por el cabestro de cerda que se usa para domarlos, amarrado al pescuezo de la bestia y asegurado al bozal en forma de rienda. Obligado a bregar con aquellos indómitos animales, en pelo o montado en una silla de madera con correas de cuero sin adobar, mis muslos sufrían tanto que muchas veces se cubrían de rozaduras que brotaban sangre. Hasta gusanos me salieron de las heridas, cosa no rara en aquellos desiertos y en aquella vida salvaje; semejante engendros produce la multitud de moscas que abundan allí en la estación de lluvias. Acabado el trabajo del día, Manuelote, echado en la hamaca, solía decirme: "Catire Páez, traiga un camazo de agua y láveme los pies"; y después me mandaba que le meciese hasta que se quedaba dormido. Siempre se me encomendaba para desempeñar cuanto había más difícil y peligroso que hacer en el hato. Cuando, algunos años después, le tomé prisionero en la batalla de "Mata de la Miel", le traté con la mayor bondad; hasta hacerle sentar a mi propia mesa; y un día que le manifesté el deseo de serle útil en alguna cosa, me suplicó como único favor que le diera un salvoconducto para retirarse a su casa. Al momento le complací, por lo que, agradecido del buen tratamiento que había recibido, se incorporó más tarde a mis filas. Entonces, los demás llaneros en su presencia solían decirse unos a otros con cierta malicia: "Catire Páez, traiga un camazo de agua y láveme los pies". Picado Manuelote con aquellas alusiones de otros tiempos, les contestaba: "Ya sé que ustedes dicen eso por mí, pero a mí me deben el tener a la cabeza un hombre tan fuerte, y a la patria una de las mejores lanzas, porque fui yo quien lo hizo hombre" ${ }^{8}$

Ciertamente, todas aquellas vicisitudes en el hato La Calzada no fueron sino el adiestramiento necesario para impulsar su excepcional desempeño en el campo de batalla como el centauro llanero. Pero... ¿Quiénes son los centauros?

\section{Centauros, semidioses y héroes en la mitología griega}

En la mitología griega, los centauros son considerados una raza de feroces seres habitantes de las regiones montañosas de Tesalia y Arcadia. Sus representaciones en los frisos y metopas del Partenón de Atenas, con forma humana de la cabeza a la cintura y con el bajo vientre y piernas de caballo, destacan su crueldad y violencia en el combate. Además, como seguidores de Dionisio - dios del vino -, se caracterizó a los centauros por su embriaguez y lascivia, lo cual les costó su expulsión de Tesalia cuando, en un frenético estado de embriaguez, intentaron raptar a la novia del rey de los lapitas en su propia fiesta de bodas. El mito abre espacio para una excepción entre los centauros, es el caso de Quirón, quien se destacó por su bondad y sabiduría, y educó a varios héroes griegos, entre ellos a Aquiles y Jasón. 
En el palacio del que era huésped, Ixión miró a Hera y la deseó para sí. Hera informó de esto a Zeus. Para descubrir la verdad, Zeus formó con nubes una imagen de su esposa; Ixión abrazó a la nube y engendró en ella una criatura semi-hombre, semi-caballo. Airado por el doble crimen de Ixión, Zeus ató al malhechor a una rueda de fuego alada que gira siempre en el aire mientras el penitente repite las palabras: '¡Debes recompensar a tu benefactor con agradecimiento!' La escena del castigo fue trasferida más tarde al Inframundo. En toda esta historia puede reconocerse con facilidad el castigo de un dios solar más viejo y salvaje, que debió ser domeñado por el gobierno de Zeus. Ixión engendró en la nube sin concurso de Cárite alguna, es decir, sin Afrodita... Del hijo de Ixión, un ser de doble aspecto llamado centauro, se decía que se ayuntaba con las yeguas del monte Pelión. Ese fue el origen de los centauros, habitantes de los bosques sobre cuyo cuadrúpedo cuerpo de caballo aparecía la parte superior del cuerpo de un hombre. ${ }^{9}$

\section{La metáfora del centauro y sus interpretaciones}

Parece lícito pensar que la metáfora del centauro, fue utilizada en el contexto de las guerras de independencia y primeros años de la República de Venezuela, para construir la representación colectiva del ejercito libertador -y especialmente de su General J. A. Páezcomo seres excepcionales, capaces de fundir en un mismo ser la inteligencia e ideales del hombre y héroe civilizador, y la ferocidad e ímpetu de un animal frente a su enemigo. Pero además, al aludir a la naturaleza mixta del centauro y su linaje divino (descendiente del dios Ixión), es posible profundizar en la interpretación de esta metáfora.
Gracias a la naturaleza mixta del centauro (mitad hombre, mitad caballo) este ser mitológico estaría en condiciones de vehicular alegorías sobre los héroes de la independencia americana en su naturaleza mixta de hombres deificados o dioses humanizados. ${ }^{10} \mathrm{Si}$ bien es cierto que la deificación de los héroes de la independencia y su culto, como "padres de las naciones que crearon a costa de sangre", es un fenómeno recurrente en la historia republicana de América; también es cierto que la figura del centauro llanero permitió enfrentar en el plano mítico al león ibérico.

\section{El centauro llanero y sus luchas contra el león ibérico}

Un aspecto importante para comprender el proceso de construcción de la nación venezolana, es la metáfora del centauro llanero como el animal símbolo de los americanos, capaz de derrotar al animal símbolo de los europeos: el león ibérico. Una cualidad bien conocida sobre el simbolismo dado al rey de España y remarcada durante la independencia de América, es su representación zoomorfa con el león. Este simbolismo es recogido en el himno de la república de argentina, que en una de sus estrofas dice:

Se levanta a la faz de la tierra

Una nueva y gloriosa nación

Coronada su cien de laureles,

Y a sus plantas rendido un león

Como es sabido, los animales símbolo permiten vehicular significaciones factibles de redefinición y utilización en la explicación y predicción de la realidad social. En este sentido, resultan de gran interés los relatos $\mathrm{y}$ antiguos escritos en piedra, referidos a las 
míticas luchas del centauro y el león, y la emblemática utilización de ambos como tótems. La presencia subyacente de estos mitos en la cultura española es referidas por Schneider, quien en su "ensayo histórico-etnográfico sobre la subestructura totemística y megalítica de las altas culturas y su supervivencia en el folklore español", señala: Una impronta de sello de Asiria y una miniatura de Samarkand muestran un centauro matando a un león. El sol, el rey, el centauro y el toro,... son... congénitos al león. Las cazas místicas del rey contra el león son luchas del sol contra el león-dragón que intenta devorar al sol. ${ }^{11}$

Es posible entonces hipotetizar que la metáfora del centauro llanero no se refirió sólo al carácter heroico de la figura ecuestre de Páez y a su feroz desempeño en la guerra, sino también a la mitificación de los líderes independentistas y sus acciones. La interpretación que los republicanos hicieron de su desempeño bélico no fue la de una simple confrontación entre individuos o grupos por el control de un territorio, sino la reedición de una lucha entre contrarios, librada desde el principio de los tiempos entre tótems del bien y del mal, entre deidades de la luz y de la oscuridad, entre la libertad y la servidumbre o, lo que para los patriotas era lo mismo, entre los republicanos y los realistas. Éste es el imaginario que inspira al ejército libertador: el sueño de representar y repetir en su comportamiento histórico la realización concreta del más colosal mito fundacional de la sociedad europea occidental, para fundar ahora la nación americana.

En el caso de la Venezuela independentista, Páez fue el mítico centauro llamado a enfrentar y derrotar al león ibérico en el campo de batalla. El himno nacional argentino fue utilizado para vehicular la imagen del león ibérico rendido a los pies de los americanos. Esta canción patriótica sirvió a Páez y sus lanceros como recurso simbólico para producir y socializar una ideología independentista, promover la representación colectiva de la república y conformar un ejército dispuesto a materializar las luchas míticas entre el centauro y el león. La redefinición y socialización de los nuevos mitos, ritos y símbolos republicanos, encontró en la música un vehículo particularmente efectivo, dadas las dotes musicales y la privilegiada voz del centauro llanero. ${ }^{12}$

\section{Páez, el centauro cantador en la etnogénesis de Venezuela}

Como es sabido, la música jugó un papel fundamental en las luchas por la independencia de las colonias hispanoamericanas. Una versión de la Carmagnola francesa en idioma español recorrió e impregnó con su ideología todas las posesiones hispanas de ultramar. El mismo Páez cantaba con sus soldados su propia versión de la Carmañola americana en los llanos centrales para el año 1817, con el título de "Canto de las Sabanas". El texto dice así:

Si acaso te preguntan por qué andáis descamisado,

(¡Avanzad! ¡Avanzad! ¡Avanzad con machete en mano!)

Decid que con sus tributos los Godos me la han quitado.

(¡Avanzad! ¡Avanzad! ¡Avanzad con machete en mano!)

Vengan, ¡Chapetones! A morir aquí;

Dexemos a la España en su frenesí. 
Páez, con su poderosa y privilegiada voz de tenor, aupaba a su guardia de honor para entonar las canciones patrióticas, incluso en el fragor de sus encarnizadas batallas. De ello dio testimonio el Capitán de la legión británica, Richard Vowel, ${ }^{13}$ quien en 1818 , lo describe en los llanos de Barinas dirigiendo a 150 llaneros que conformaban su guardia de honor, mientras cantaban precisamente el Himno Nacional Argentino, luego de una sangrienta lucha ${ }^{14}$. Este Himno, que fortaleció el sentimiento de unidad y el liderazgo incuestionable de Páez desde sus primeros años en la lucha independentista, era conducido personalmente por él, e interpretado a coro por sus llaneros, de la misma manera que con su voz y autoridad conducía a sus lanceros en la batalla. La letra completa del Himno de Argentina dice así:

¡Oíd mortales el grito sagrado: ¡Libertad! ¡Libertad! ¡Libertad! Oíd el ruido de rotas cadenas, $\mathrm{Y}$ ensalzad a la noble igualdad.

Se levanta a la faz de la tierra Una nueva y gloriosa nación Coronada su cien de laureles, Y a sus plantas rendido un león.

$¡$ Sean eternos los laureles Que supimos conseguir! ¡Coronados de gloria vivamos Juremos con gloria morir

Coro

Sean eternos los laureles Que supimos conseguir. Coronados de gloria vivamos, O sepamos con gloria morir

Páez arengó a su guardia de honor para entonar, interiorizar y representar en su propio desempeño el contenido mítico de esta y otras canciones patrióticas, especialmente en los momentos de mayor angustia, circundantes al fragor de sus batallas. Ciertamente, Páez interpretó y utilizó diversas músicas para construir y vehicular representaciones colectivas sobre aspectos extra musicales como la emancipación y los sentimientos patrióticos, especialmente cuando la patria americana, libre e independiente de España, era sólo una idea con pocas probabilidades de éxito. Diversos documentos escritos reseñan las habilidades musicales del centauro llanero y la utilización de estas para interpretar canciones cuyo contenido promovía la ideología independentista. No obstante, ninguna de aquellas músicas se extendería hasta nuestros días con tan significativo impacto en la conformación de la nación venezolana como la música del joropo y sus "corríos".

Muchos corríos, de política intención, que en los llanos se cantaron en tiempos de la Guerra Grande, y que después se extendieron a otros puntos del país, fueron fruto de su ingenio: sus corríos ocasionaron defecciones en las huestes de Ceballos, Boves y de Morales: el Negro Infante, dice que fue conquistado por uno de esos corríos, y, de enemigo jurado, se convirtió en un perro fiel de Bolívar. ${ }^{15}$

También la historia oral, a través de cantos, poesías y leyendas, ha conservado $\mathrm{y}$ transmitido por generaciones importantes datos sobre este aspecto. En ellos Páez es descrito como guerrero, cantador de joropos, maraquero y guitarrista (cuatrista); capaz de improvisar galerones acompañándose con el cuatro, y cantar corríos al pié del arpa, solo o en contrapunteo. 
La determinante participación de Páez y los llaneros en la fundación de la nación, terminó expandiendo la música de esa región por todos los confines de Venezuela. Desde entonces y hasta el presente, la música del joropo, ha sido representativa no sólo de la región llanera del país, sino del paisaje sonoro de toda la patria. La misma ideología nacionalista que terminó derrumbando los imperios para dar paso al surgimiento de las naciones, se ha ocupado de incentivar el desarrollo de una sensibilidad especial hacia determinadas músicas en cada país. En el caso venezolano, es fundamentalmente el joropo la música que evoca la etnogénesis de Venezuela y con ella la identidad nacional de esta patria ${ }^{16}$. Ese mismo proceso de reacomodos y redefiniciones, involucró no sólo mitos, símbolos y músicas, sino también a los personajes que libraron la guerra de independencia. Analicemos cómo se da ese proceso en el caso del general Páez. Veamos cómo el peón de hato se convierte en el Centauro Llanero.

\section{El centauro frente a las ambigüedades de la revolución independentista}

La representación colectiva del general José Antonio Páez como el centauro llanero, se construye en un periodo histórico de particular confusión y carencia (o cuando menos insipiencia) de símbolos identitarios consolidados que permitiesen establecer claramente las ideologías y los bandos en pugna. Una de las razones de aquella ambigüedad era precisamente la participación en el ejercito republicano de quienes antes habían sido parte o habían prestado servicios al ejército del rey de España. Es este el caso de:
1. Simón Bolívar, incursionando en el ejército del rey y al servicio de la monarquía española, y posteriormente separándose de él, para convertirse en su más pertinaz enemigo.

2. José Antonio Páez, prestando servicios a Antonio Tiscar y Pedrosa y su ejército realista.

3. Los lanceros de José Tomás Boves, quienes en principio derrotan a los republicanos y luego de la muerte de su caudillo se convierten en el factor más decisivo de sus victorias, bajo el mando de Páez.

En ese paradójico contexto histórico asistimos a la construcción simbólica de dioses de la Libertad como Bolívar y San Martin; y semidioses como El Centauro Llanero. En esta última figura se articulan los antiguos mitos fundacionales de la sociedad occidental con los códigos y símbolos propios de los llaneros venezolanos.

Esta conjunción de elementos culturales permitió redefinir la identidad de Páez y los llaneros que luchaban a su lado, para representarlos como un ejército de héroes llamados a crear la República. En este sentido, es necesario señalar que en principio, los llaneros no se inclinaron por los ideales de realistas o patriotas, sino por el caudillo que representase su identidad étnica y pudiese comandarlos para garantizarles su supervivencia. Era ésta la imprescindible divisa que debía mostrar el líder que aspirara recibir la adhesión y fidelidad de los llaneros.

En general, pertenecer a un grupo étnico - cual era caso de estos llaneros -, es ser copartícipes en la identificación, el usufructo 
y el reconocimiento (más o menos consciente) de un código cultural que genera solidaridades afectivas naturales hacia quien lo porta.

... hay aspectos de las identidades -códigos simbólicos- que son involuntarios, aprendidos por la fuerza de la presencia de ellos en la vida diaria, su objetivación es la que permite reconocerse con cierta continuidad en el devenir del tiempo. La rutina los hace... naturales... En estos códigos están inmersos los nexos de solidaridad y pertenencia a todas las prácticas institucionales... ${ }^{17}$

Fue precisamente la ausencia de estos códigos identitarios en los discursos de las elites realistas y republicanas, la que generó la "indiferencia y neutralidad" de gran parte de la población americana frente a la causa independentista, y es precisamente contra esa indiferencia que se lanzó el Decreto de Guerra a Muerte. Este decreto es el marco jurídico que mejor expresa ese momento histórico y cultural, por cuanto vierte una carga de significado inédita a las acciones que, a partir de ese momento y según fuese el caso, podían significar la vida o la muerte de las personas. Este decreto, proclamando por Bolívar el 15 de junio de 1813, en la ciudad de Trujillo de Nuestra Señora de la Paz, concluye: “...Españoles y canarios, contad con la muerte, aun siendo indiferentes, si no obráis activamente en obsequio de la libertad de Venezuela. Americanos, contad con la vida, aun cuando seáis culpables".

A partir de ese momento la confusión, la indiferencia o la neutralidad podían costar la vida. Por ello, el mismo Páez tuvo que asumir su defensa ante el ejército republicano y la Historia, para excusar el servicio realizado al ejército realista comandado por Tiscar. En su autobiografía, Páez señala:

Nunca serví en las tropas del rey, y es probable que la errónea suposición de algunos historiadores que dicen lo contrario, haya tenido origen en la mencionada entrevista con Tíscar, la remisión del despacho de que he hablado antes y el desempeño de la comisión que se me dio para recoger ganado y que tuve que cumplir contra mi voluntad. ${ }^{18}$

Días después del Decreto de Guerra a Muerte, Páez se incorporó a las tropas republicanas que mandaba Pulido en Santa Bárbara de Barinas, quien para conquistarlo para la causa republicana -luego de aquel servicio para el aprovisionamiento del ejército de Tiscar- le dio el mismo cargo que había rechazado en el ejército realista. En palabras de Páez: “...el gobierno de Barinas me confirió el grado de capitán en el ejército patriota, como recompensa por haberme negado a aceptar el mismo nombramiento en el ejército español ${ }^{19}$. Con Pulido siguió Páez hasta la ciudad de Barinas, que había sido evacuada por los realistas como consecuencia de la ofensiva del brigadier Simón Bolívar en su Campaña Admirable.

El 6 de agosto de 1813, Bolívar entró victorioso en Caracas, encabezando su ejército, luego de realizar su Campaña Admirable. Esta acción dio inicio a la llamada "Segunda República", periodo cuya necesidad más urgente era crear condiciones para la gobernabilidad y superar la confusión e indiferencia, creando símbolos y fronteras étnicas claras entre realistas y republicanos. Para ello se realizaron tres acciones concretas: 
1. Formar dos centros de gobierno republicano: uno en Caracas al mando de Bolívar y otro en Cumaná, dirigido por Santiago Mariño.

2. Conferir del título de Libertador a Simón Bolívar, otorgamiento realizado por parte del pueblo y la Municipalidad de Caracas.

3. Fusilar los prisioneros españoles y canarios de Caracas y La Guaira, orden dada por Bolívar como implementación de la "Guerra a Muerte".

Pese a estas acciones, aún se hacía difícil el establecimiento de fronteras étnicas y la conformación de bandos claramente definidos para dar forma a la guerra y vislumbrar algún final a lo que debía ser una lucha de contrarios. La mayor dificultad que se enfrentaba en medio de aquella guerra, promovida por las elites de españoles peninsulares y españoles americanos, radicaba en que estos últimos constituían la extensión genética y cultural de los primeros. La inevitable indefinición de símbolos y fronteras étnicas entre los grupos en conflicto dio lugar a diversas insurrecciones anárquicas, entre las que se destaca la de los llaneros acaudillados por José Tomás Boves, la cual adquirió el carácter de rebelión social a partir del segundo semestre de 1813.

Boves y sus llaneros, en un primer momento simpatizantes del movimiento republicano, terminan aliándose con los realistas, luego desconociendo las órdenes de éstos, y finalmente terminaron convertidos en una rebelión de pardos, mestizos y negros fuera del control de realistas y republicanos. Tras reiteradas victorias para los realistas (frecuentemente apoyados por los lanceros de Boves), cae la "Segunda República", en febrero de 1814, habiendo sido el periodo de mayor intensidad en la aplicación del Decreto de Guerra a Muerte y el de la designación de Bolívar como El Libertador: un símbolo que aún no lograba consolidarse plenamente en las representaciones colectivas de la sociedad.

Para este momento, Páez también ha comenzado tímidamente su ascenso y figuración en el ejército patriota. Recibe órdenes en Barinas de atacar al comandante realista Miguel Marcelino, quien ocupaba a Canaguá con unos 400 soldados de caballería. Páez sale a cumplir la orden y el 27 de noviembre de 1813, sorprende y derrota a Miguel Marcelino, cayendo prisionero la mayor parte de su ejército. Es el primer triunfo de Páez. Posteriormente fue a Mérida y sirvió bajo las órdenes del comandante Antonio Rangel.

En la población de Estanques, Páez tuvo un encuentro bélico con José María Sánchez, quien era un sanguinario muy temido por todos los merideños. En la refriega resultó muerto Sánchez, y Páez, siguiendo las tropas del General Urdaneta -quien se dirigía a Nueva Granada-, llegó hasta Bailadores, pero allí, disgustado porque el jefe de caballería le ordenó que le entregara su caballo a otro oficial, se separó de ellos, resentido. Después de unos días de meditación concibió la idea de irse a los llanos y conquistar para el ejército patriota a los mismos hombres que habían luchado bajo las órdenes de los realistas Boves, Calzada y Yánez. A todos los generales patriotas les pareció una idea descabellada, pero Páez la puso en práctica, y con una decisión temeraria, se fue a los llanos y reclutó a muchos de aquellos 
llaneros para el ejército republicano, lo cual se tradujo en un factor decisivo para las posteriores victorias de los patriotas. Los mismos lanceros que antes habían derrotado al ejército patriota, ahora luchaban a su favor bajo las órdenes de Páez.

Es evidente que quitar a Boves e instaurar a Páez como símbolo de su unidad, no constituyó para los lanceros el producto de una sesuda reflexión sobre el sistema monárquico o republicano, sino del reconocimiento en Páez de los códigos simbólicos propios de los llaneros, ante los cuales no podían ser indiferentes, como sí podían serlo (y efectivamente lo fueron) frente a los encendidos discursos ideológicos esgrimidos por realistas y patriotas en la etérea y elitesca confrontación de sus universos simbólicos ${ }^{20}$.

Con sus lanceros, Páez venció en diversos combates, entre ellos los de Mantecal, y Mata de la Miel. En este último lugar sorprendió al Coronel Francisco López y le hizo más de cuatrocientos prisioneros, además, quedaron en su poder una importante cantidad de caballos y todo el equipo de guerra.

Páez recibió orden del coronel Miguel Valdés de asistir en la Villa de Arauca a una junta de oficiales de Nueva Granada y Venezuela, a fin de conformar el gobierno provisorio conocido como el Gobierno de Guasdualito. En esa junta fueron elegidos el teniente coronel Fernando Serrano como presidente, y el coronel Francisco de Paula Santander como comandante general del ejército, entre otros. Para septiembre de ese año 1816, considerando la importancia de Páez y sus lanceros para el desenvolvimiento de la guerra, se reúne nuevamente la junta de oficiales y se propone un jefe único en quien confiasen los llaneros para que los condujese en la guerra. Esa junta -compuesta por los coroneles Juan Antonio Paredes y Fernando Figueredo; los tenientes coroneles José María Carreño, Miguel Antonio Vásquez, Domingo Meza y José Antonio Páez; y el sargento mayor Francisco Conde-, procedió a elegir a la persona que según ellos debía desempeñar simultáneamente las funciones de Serrano y Santander; es decir, un jefe absoluto de los llanos. La elección no podía recaer en otra persona sino en Páez, quien a partir de ese momento (septiembre de 1816) fue ascendido a general de brigada.

Inmediatamente se sucedieron importantes triunfos para Páez como los de El Yagual (el 11 de octubre de 1816), y Mucuritas (el 28 de enero de 1817) donde derrota al brigadier Miguel de la Torre luego de prenderle fuego a la sabana y hacer repetidas cargas de caballería contra la infantería realista, la cual se salvó de morir abrasada gracias a una hondonada con agua por la cual escapó. Ese año de 1817, continuaron las victorias de Páez en San Antonio de Apure (13 de abril), paso de Apurito (18 de junio), paso de Utrera (20 de junio), Barinas (14 de agosto) y Apurito (8 de noviembre). Esa formidable campaña bélica fue el preludio del encuentro que sostuvo el 30 de enero de 1818 el general de brigada José Antonio Páez con el general en jefe Simón Bolívar, quien venía de Angostura con su ejército realizando la Campaña del Centro. El encuentro de ambos jefes y sus ejércitos sería decisivo en las operaciones contra el ejército del general Pablo Morillo, y para la Independencia de América. 
Las operaciones comenzaron con la Toma de las Flecheras, una maniobra ideada por Páez y en la cual 50 de sus lanceros capturaron las naves realistas que permitieron al ejército libertador cruzar el río Apure por el paso del Diamante. El 12 de febrero de 1819, Páez dirige la vanguardia como comandante del ejército patriota en la batalla de Calabozo, en la cual es derrotado Morillo. Luego combate en la Uriosa (15 de febrero), El Sombrero (16 de febrero), y el 22 de ese mes recibe el nombramiento de gobernador de Barinas y la misión de liberar a San Fernando de Apure, lo cual realiza el 8 de marzo. Luego de estos triunfos y otros en enfrentamientos menores, Páez, al frente de 150 lanceros, derrota al ejército realista del general Morillo, comandado por el teniente coronel Narciso López, en Las Queseras del Medio, el 2 de abril de ese año de 1819. El propio Páez relata esta hazaña en su autobiografía:

Un oficial de la caballería realista se pasó a nosotros y antes de presentarse al Jefe Supremo (a Bolívar), nos informó que Morillo había organizado un plan para hacerme prisionero. Después de esto corrió a ver a Bolívar, y habiéndole referido el plan de Morillo, le dije que si él me permitía pasar el río (El Arauca) con un cierto número de los míos, yo con mi táctica habitual atraería a los realistas hasta frente al lugar donde estábamos, y si él (Bolívar) emboscaba en las orillas del río las compañías de cazadores con la artillería, podíamos dar un buen golpe a los realista, pues yo cargaría de frente en aquel momento, mientras las fuerzas emboscadas atacaban de flanco. Accedió Bolívar a mis deseos e inmediatamente con ciento cincuenta hombres crucé el río, y al galope nos dirigimos al campamento de Morillo. Movióse éste y nosotros le fuimos entreteniendo con frecuentes car- gas y retiradas hasta llevarlo al punto que habíamos convenido para la emboscada: Muy apurada era nuestra situación, pues el enemigo nos venía acorralándolo por ambos costados con su caballería, y nos acosaba con el fuego de sus fusiles, cuando afortunadamente el valeroso comandante realista Narciso López me brindó la oportunidad de pasar a la ofensiva. López se adelantó a la caballería con el escuadrón de carabineros que mandaba. En el acto después que el comandante Rondón, un hombre de gran valor, le atacase a viva lanza y se retirara sin pérdida de tiempo antes de que lo cercasen las dos alas de la caballería enemiga, que yo deseaba que formasen una sola masa, para entonces volver riendas nosotros y atacarlos de firme. ${ }^{21}$

Páez, al relatar estos momentos de gloria, aporta algunas de las más célebres páginas de la historia patria venezolana. En ellas, no duda en calificar sus hazañas y las de sus lanceros como la reedición de las más grandes proezas de los dioses y héroes de la antigua Grecia. A continuación, una parte del relato de Páez, refiriendo la hazaña realizada por él, Rondón y el resto de sus lanceros:

Cargó Rondón con la intrepidez del rayo, y López imprudentemente echó pie a tierra con sus carabineros. Rondón le mató a alguna gente y pudo efectuar la retirada sin que lograsen cercarlo. Al ver que las dos secciones de la caballería (enemiga) no formaban más que una sola masa, para cuyo objeto había ordenado el movimiento a Rondón, mandé a mi gente volver riendas y acometer con el brío y coraje con que sabían hacerlo en los momentos más desesperados. Entonces la lanza, arma de los héroes de la antigüedad, en manos de mis ciento cincuenta hombres, hizo no menos estragos de los que produjera en aquellos tiempos que cantó Homero. Es tradición que trescientos espartanos, a la boca de un desfiladero, sostuvieron hasta morir, con 
las armas en la mano, el choque de las numerosas huestes del rey de Persia, cuyos dardos nublaban el sol: cuéntase que un romano solo disputó el paso de un puente a todo un ejército enemigo. ¿No será con eso comparable el hecho ejecutado por los cientos cincuenta patriotas del Apure? Los héroes de Homero y los compañeros de Leonidas sólo tenían que habérselas con el valor personal de sus contrarios, mientras que los apureños, armados únicamente con armas blancas, tenían también que luchar con ese elemento enemigo que Cervantes llama 'diabólica invención, con la cual un infame y cobarde brazo, que tal vez tembló al disparar la máquina, corta y acaba en un momento los pensamientos y la vida de quien merecía gozar luengos años'. Cuando vi a Rondón recoger tantos laureles en el campo de batalla, no pude menos que exclamar: ¡Bravo, bravísimo, comandante!. General -me contestó él-... así se baten los hijos del Alto Llano. Todo contribuía a dar a aquel combate un carácter de horrible sublimidad: la noche que se acercaba con sus tinieblas, el polvo que levantaban los caballos de los combatientes de una y otra parte confundiéndose con el humo de la pólvora, hacían recordar el sublime apóstrofe del impetuoso Ayax cuando pedía a los Dioses que disipasen las nubes para pelear con los griegos a la clara luz del sol. La caballería enemiga se puso en fuga; la infantería se salvó echándose sobre el bosque y la artillería dejó sus piezas en el campo, lo cual no pudimos ver por la oscuridad de la noche. Finalmente, mucho antes de amanecer se puso Morillo en retirada para Achaguas. ${ }^{22}$

Señala Páez que los muertos del ejército realista ascendieron a casi quinientos; mientras que él sólo tuvo cuatro heridos y dos muertos. Bolívar, quien con los demás jefes del ejército había presenciado la batalla, no dudó en calificar aquella hazaña como la más extraordinaria de las proezas mi- litares de todas las naciones. Terminada la acción bélica entregó la Cruz de los Libertadores a los ciento cincuenta lanceros y la proclama "A los Bravos del Ejército de Apure". Esta proclama dice así:

Soldados! Acabáis de ejecutar la proeza más extraordinaria que puede celebrar la historia militar de las naciones. Ciento cincuenta hombres, mejor diré ciento y cincuenta héroes, guiados por el impertérrito Páez, de propósito deliberado han atacado de frente a todo el ejército español de Morillo. Artillería, infantería, caballería, nada ha bastado al enemigo para defenderse de los ciento y cincuenta compañeros del intrepidísimo Páez. Las columnas de caballería han sucumbido al golpe de nuestras lanzas; la infantería ha buscado un asilo en el bosque; los fuegos de sus cañones han cesado delante de los pechos de nuestros caballos. Sólo las tinieblas habrían preservado a ese ejército de viles tiranos de una completa y absoluta destrucción. '¡Soldados! Lo que se ha hecho no es más que el preludio de lo que podéis hacer. Preparaos al combate, y contad con la victoria que lleváis en las puntas de vuestras lanzas y de vuestras bayonetas'" (Simón Bolívar, Proclama Firmada en el Cuartel General de los Potreritos Marreñeros, a 3 de abril de 1819).

La fiereza de Páez y sus lanceros en la batalla no sólo les hizo merecedores del reconocimiento de los patriotas, sino también de las más insólitas hipérboles de los realistas, quienes les representaban como seres sobrenaturales. En su reporte militar, el historiador del general Pablo Morillo -Torrente-, escribe que el ejército realista había sido vencido por "...quinientos llaneros de figura gigantesca y de hercúlea musculatura". ${ }^{23}$

Las reiteradas victorias y hazañas de Páez y sus lanceros a caballo; la procla- 
ma de Bolívar resaltando la impotencia de los cañones realistas frente al pecho de los caballos de los "ciento y cincuenta héroes, guiados por el impertérrito Páez"; el uso que hace el mismo Páez de las figuras épicas de la mitología griega (como el legendario Ayax) para representar su valor y el de sus lanceros en la batalla; y los testimonios de los realistas sobre "las gigantescas y hercúleas musculaturas de los lanceros", no tardaron en configurar en el imaginario colectivo la representación de Páez como un ser extraordinario, un héroe civilizador. En resumen, un semidiós: el Centauro Llanero bajo cuya imponente égida podía nacer, y de hecho nació en 1830, una nueva nación, la República de Venezuela. ${ }^{24}$

El 6 de mayo de 1873 murió Páez exiliado en Nueva York, pero la resonancia de su imponente imagen, mitificada por patriotas y realistas, se extendió a través del espacio y el tiempo, adquiriendo una función simbólica fundamental en la construcción de la nación venezolana.

\section{Abstract}

This article is dedicated to the study of nationalism and independence of the Venezuelan nation, focuses on the collective representation of General Páez, as the Centaur Ranger, for under the aegis of this legendary figure was created the Republic of Venezuela, as a free nation and independent of the Gran Colombia, in 1830. Interpreting this figure in the context of independence, it is evident that the founding myths of the current Latin American nations were built redecorating the ancient myths of
Western, Native American and African American societies. The redefinition of those myths, with their heroes and antiheroes, oppressors and liberators, gave substance to the representations, ethnicities and ideologies that under the garb of nationalism, produced cleavage of empires and the emergence of the present republics.

Keywords: Founding myths. Symbols of identity. War of Independence.

\section{Resumen}

Este artículo, dedicado al estudio del nacionalismo e independencia de la nación venezolana, se centra en la representación colectiva del general Páez, como el Centauro Llanero, pues bajo la égida esta mítica figura nació en 1830 la República de Venezuela, como nación libre e independiente de la Gran Colombia. Al interpretar esta figura en el contexto independentista, se evidencia que los mitos fundacionales de las actuales naciones latinoamericanas, se construyeron con los redecorados de los antiguos mitos de las sociedades occidentales, indoamericanas y afroamericanas. La redefinición de aquellos mitos, con sus héroes y antihéroes, opresores y libertadores, dio fundamento a las representaciones, etnicidades e ideologías que bajo los ropajes del nacionalismo, produjeron la escisión de los imperios y el surgimiento de las actuales repúblicas.

Palabras clave: Guerra de Independencia. Mitos fundacionales, Símbolos identitarios. 


\section{Notas}

1 García Gavidia, N. 1987. Posesión y Ambivalencia en el Culto a María Lionza: Maracaibo: Editorial de La Universidad del Zulia, 1987, p. 87.

2 Archivo General de la Nación, Tomo XXVI, expediente n. 2, año 1815.

3 Idem.

4 ARCINIEGAS, G. Bolívar: el hombre de la gloria. Bogotá: Tercer Mundo, 1983.

5 LUDWIN, E. Bolívar el caballero de la gloria y la libertad. Ciudad de México: Diana, 1966.

6 Ver, entre otros, CARRERA DAMAS, G. El culto a Bolívar. Caracas: Edic. UCV, 1973.

7 POLANCO ALCÁNTARA, T. 2001. José Antonio Páez. Fundador de la República. Barcelona: Edic. GE, 2001.

8 PÁEZ, J. A. 1946. Autobiografía de José Antonio Páez. Tomos I y II. Caracas: Librería y Editorial del Maestro, 1946, p. 8-11.

9 KERÉNYI, K. Los dioses de los griegos. Caracas: Monte Ávila, 1997, p. 159.

10 ROSE, H. J. Mitología Griega. Barcelona: Labor, 1970.

11 Schneider, M. El origen musical de los animales-símbolos en la mitología y la escultura antiguas. Madrid: Siruela. 1998, p. 115.

12 El musicólogo venezolano Vicente Emilio Sojo (1887-1974), señala que el General José Antonio Páez poseía una voz poderosa y con la tesitura de un eminente tenor. Reportando lo que el Dr. Adolfo Carranza decía de Páez, Sojo escribió: “Páez (tenía entonces 78 años), poseía una voz poderosa, con la que cantaba el Miserere de El Trovador; y, con agilidad increíble saltaba tarareando canciones andaluzas". SOJO, V. E. Algunas noticias acerca de las aficiones musicales del General José Antonio Páez. Caracas: Edic. Ministerio de Educación, 1954, p. 3. Al referirse a la "Flor del Retiro", un valse lento cuya letra y música fueron compuestos por Páez durante su exilio en Buenos Aires, Sojo señala: “...la música se elevaba cuatro veces hasta el do agudo (el nunca bien alabado do de pecho de El Trovador), y a los 78 años de edad lo cantaba sin que el gallo apareciera" Ibidem, p. 5.

13 En 1817, el capitán inglés Richard Vowel, se alistó en el 1er. Regimiento de Lanceros del Ejército Libertador de Simón Bolívar, comandado por el general Páez. En su libro "Las sabanas de Barinas" Vowel relata como un hecho particularmente significativo, la arenga del general Páez, motivando a 150 llaneros de su guardia a que entonaran una canción patriótica compuesta por un fraile dominico de Buenos Aires, adoptado en diversas latitudes de Sur América: el Himno Nacional de la República Argentina.
14 Sojo, op. cit.

15 Ibidem, p. 4.

16 Como es sabido, el joropo es una forma musical derivada del fandango español que luego de un intenso proceso de reelaboraciones y redefiniciones ideológicas experimentadas de manera muy especial durante los años de la guerra independentista, se convirtió en la música representativa de la nación venezolana CRIVILLÉ BARGALLÓ, J. Historia de la Música Española. Madrid: Alianza Editorial, 1983; CHOURIÓN, J. J. “El Joropo o el jarabe venezolano". El Nuevo Diario. Caracas, 13/1/1916; CALDERÓN, C. "Estudio analítico y comparativo sobre la música del joropo, expresión tradicional de Venezuela y Colombia". Revista Musical de Venezuela. Caracas: Edit. Fundación Vicente Emilio Sojo y Conac. No. 39. 1999, p. 219-258; Mora Queipo, et al. Músicas y mitos en la construcción de la nación venezolana. En Ligia Berbesí y Belín Vásquez (Compiladoras). Vínculos y Sociabilidades en España e Iberoamérica; Siglos XVI-XX. Maracaibo: Ediluz, 2010, p. 291-313. Así, mientras para el musicólogo caraqueño José Antonio Calcaño (1900-1978) el "tono llanero" (el joropo) es la más fiel imagen de esa región; para su colega y coterráneo Juan Bautista Plaza (1898-1962), la música del "tono llanero" tiene la particular virtud de evocar no sólo el paisaje de esa región, sino el de toda la nación PLAZA, J. B. 1991. El Lenguaje de la Música. Caracas: Ediciones Alfadil, 1991.

17 GARCÍA GAVIDIA, N. "El uso de símbolos indígenas en la invención de la identidad nacional". Revista Opción. n. 40, 2003, p. 9-34, p. 27.

18 PÁEZ, J. A. 1946. Autobiografía de José Antonio Páez. Tomos I y II. Caracas: Librería y Editorial del Maestro, 1946, p. 28.

19 Idem.

20 MEDINA C.; MORA QUEIPO E. El Obispo Lasso de la Vega en la confrontación de universos simbólicos de la época independentista. Revista Ágora. n. 10, 2002, p. 155-179.

21 PÁEZ, J. A. op. cit, p. 181.

22 Ibidem, p. 182.

23 Ibidem, p. 184.

24 MARTÍNEZ, C. 1947. Litografía de Páez a caballo, espada en mano. Se conserva en el Museo Histórico Militar de San Mateo (Estado Aragua) Venezuela, 1947; COVA, J. El Centauro: vida del general José Antonio Páez. Buenos Aires: Edit. Venezuela, 1947; NUCETE, J. 1968. José Antonio Páez: el héroe centauro. Caracas: Edime, 1968; PÉREZ, M. 1973. El Centauro del Llano. Caracas: Centro Simón Bolívar, 1973. 


\section{Bibliografia}

ANDERSON, B. Comunidades Imaginadas. Reflexiones sobre el origen y la difusión del nacionalismo. Ciudad de México: Fondo de Cultura Económica, 1997.

ARCINIEGAS, G. Bolívar: el hombre de la gloria. Bogotá: Edit. Tercer Mundo, 1983.

CARRERA DAMAS, G. El Culto a Bolívar. Caracas: Edic. UCV, 1973.

CALDERÓN, C. Estudio analítico y comparativo sobre la música del joropo, expresión tradicional de Venezuela y Colombia. Revista Musical de Venezuela. Caracas: Edit. Fundación Vicente Emilio Sojo y Conac. n. 39. 1999, p. 219-258.

COVA, J. El superhombre: vida y obra del Libertador. Caracas: Las Novedades, 1943.

El centauro: vida del general José Antonio Páez. Buenos Aires: Venezuela, 1947.

CRIVILLÉ BARGALLÓ, J. Historia de la música española. Madrid: Alianza Editorial, 1983.

CHOURIÓN, J. J. El Joropo o el jarabe venezolano. El nuevo diario. Caracas, 13/1/1916.

GARCÍA GAVIDIA, N. El uso de símbolos indígenas en la invención de la identidad nacional. Revista opción. n. 40, 2003, p. 9-34.

HOBSBAWM, E. Naciones y nacionalismo desde 1780. Barcelona: Crítica, 2004.

KERÉNYI, K. Los dioses de los griegos. Caracas: Monte Ávila, 1997.

LUDWIN, E. Bolívar el caballero de la gloria y la libertad. Ciudad de México: Diana, 1966.

MARTÍNEZ, C. Litografía de Páez a caballo, espada en mano. Se conserva en el Museo Histórico Militar de San Mateo (Estado Aragua) Venezuela, 1947.

MEDINA C.; MORA QUEIPO E. El Obispo Lasso de la Vega en la confrontación de universos simbólicos de la época independentista. Revista Ágora. n. 10, 2002, p. 155-179.
MORA QUEIPO, E.; GONZÁLEZ QUEIPO, J. El tenor de las lanzas coloradas. Páez y el joropo en la identidad nacional venezolana. En Clarac, Gordones y Meneses. Lecturas Antropológicas de Venezuela. Edic. Universidad de los Andes, 2007, p. 729-736.

MORA QUEIPO, E.; GONZÁLEZ QUEIPO, J.; RICHARD, D. El centauro llanero. Sus mitos y símbolos en la identidad nacional venezolana. Revista Opción. n. 53. Maracaibo, 2007, p. 91-111. MORA QUEIPO, E.; GONZÁLEZ QUEIPO, J.; RICHARD DE MORA, D.; FERREIRA DE MORA, I. Músicas y mitos en la construcción de la nación venezolana. En Ligia Berbesí y Belín Vásquez (Compiladoras). Vínculos y Sociabilidades en España e Iberoamérica; Siglos XVI-XX. Ediluz. Maracaibo, 2010, p. 291-313.

NUCETE, J. José Antonio Páez: el héroe centauro. Caracas: Edime, 1968.

PÁEZ, J. A. Autobiografía de José Antonio Páez. Tomos I y II. Caracas: Librería y Editorial del Maestro, 1946.

PÉREZ, M. El centauro del llano. Caracas: Centro Simón Bolívar, 1973.

PLAZA, J. B. El Lenguaje de la Música. Caracas: Ediciones Alfadil, 1991.

POLANCO ALCÁNTARA, T. José Antonio Páez. Fundador de la República. Edic. GE. Barcelona (España), 2001.

RAMÓN Y RIVERA, L. F. El Joropo, Baile Nacional de Venezuela. Caracas: Ernesto Armitano Editor, 1987.

ROSE, H. J. Mitología griega. Barcelona: Labor, 1970.

SOJO, V. E. Algunas noticias acerca de las aficiones musicales del General José Antonio Páez. Caracas: Ministerio de Educación, 1954.

VOWEL, R. Las Sabanas de Barinas. Caracas: Ministerio de Educación-Academia Nacional de la Historia, 1988. 